method of treatment is neither encouraged by physicians nor readily approved of by patients except as a "forlorn hope."

Under these circumstances I beg to recommend the following method of opening the stomach at one operation with power to feed the patient at once. The proceeding is very simple. The preliminary stages of the operation are conducted as usual, but when the stomach is picked up a portion of it is drawn out of the wound, and two running sutures of fairly stout silk are passed in a circle round the site of the intended opening (A) with their ends in opposite directions, care being taken not to include the mucous membrane. The opening is then made, and, each side of it being grasped with artery forceps, one of my small ( $\frac{3}{8}$ in.) intestinal glass drainage-tubes is inserted, and the ligatures are drawn tight and tied. The exposed part of the stomach is now washed and returned into the abdomen, the external wound drawn together with fishing-gut sutures, and the ends of the stomach ligatures tied over two glass rods $(3,3)$ crossing the wound, in order that the stomach may be kept in close contact with the peritoneal surface of the abdominal wall The wound is then powdered with iodoform, dressed with cyanide gauze and salicylic wool, and a bandage applied, a piece of jaconet being placed outside over the dressings to preserve them from becoming soiled. The experience of many bowel cases has shown me that these tubes separate between the third and the seventh days; therefore, from the moment of the completion of the operation to the third day the administration of food or washing out the stomach may be carried on with impunity. On the morning of the third day the wonnd should be dressed, and from this time until the tube separates, and it is clear that good adhesions have formed, discretion should be exercised as to the amount of food given and the care with which it is administered. If one may judge by analogy, experience with the colon and with one case of gastrostomy seems to show that when the tube separates the surrounding adhesions are sound and strong, and the fistulous opening is safe and efficient. The operation employed in this way is rapid and easy. The original wound may be much smaller than that usually recommended for gastrostomy, and the early stages of repair are conducted under such absolutely safe conditions as regards leakage that the personal supervision of the surgeon is quite unnecessary, a matter of considerable importance in private practice. In colotomy, especially, cases must often be left in the entire charge of the practitioner, who probably bas no desire to be responsible for completing the final stage of the operation by rimself a few days later. With the glass tube ligatured into the sigmoid or cæcum $I$ have so left cases with out seeing them again, and in no instance has the practitioner had the least cause for anxiety.

The details of the only case of gastrostomy in which I have had the opportunity of using the tube may be very shortly given. They indicate that its use is as safe in the stomach as in the bowel, but this particular case proved to be a peculiarly unfortunate one to have selected for the operation, as the growth had already crept from the cardiac to the pyloric end of the stomach and blocked both orifices. The man who was the subject of the operation was under the care of $\mathrm{Mr}$. J. H. Evans of Waterloo, with whom and with Dr. Glynn I saw him in consultation. He had malignant stricture of the cesophagus at the cardiac orifice of the stomach, by which the latter was rendered almost impervious, and he was suffering intensely from deprivation of food and from thirst. had seen several consulting physicians in London, Edinburgh, and elsewhere, and the general advice had been to leave things alone until the symptoms became urgent. This was certainly the case at that time. I tried on two occasions to pass a bougie. Both attempts were unsuccessful, though the second one was thorough and prolonged, and was borne by the patient with marked patience and fortitude. He now willingly accepted the prospect offered by gastrostomy, and being almost in extremis and most urgently in need of immediate relief I deemed it to be a suitable case in which to employ the above-suggested plan of perfoiming the operation in one stage. It was carried out exactly on the lines indicated without hitch or difficulty of any kind, and when the patient was put back to bed his condition had scarcely altered for the worse. As soon as the clip on the rubber tube was removed with the intention of passing a little peptonised milk-and-brandy into his stomach there escaped nearly a pint of foul, thin, yellow fluid, containing about fifty almost nnaltered dried currants. The organ was therefore washed out with warm water before introducing the nourishment. The introduction of finid into the stomach was effected by simply attaching a funnel to tine free end of the rubber tube. We found on inquiry that the last possible occasion on which currants could have been swallowed was at least six or seven weeks previously; it was therefore evident that they had been retained in the stomach ever since and that the growth must long ago have extended alosg the lesser curvature and blocked the pylorus. The subsequent course of the case corroborated this view, for many more currants were washed out, and though we were able to and did inject a sufficient quantity of fluid food, apparently very little was absorbed in the presence of the foul cancerous discharge. The thirst continued, the emaciation rapidly progressed, and the patient died from starvation without any febrile disturbance and without any sign of abdominal pain five days after the operation. In the meantime the tube beld perfectly for three days and a half, when, as fluid began to escape beside it, I removed it ; but good adhesions had formed and the fistulous opening was safe for use. During the last two days of his life we washed out the stomach and injected the food through the opening as easily as before, though unfortunately he derived no more benefit from it. It was not possible to make a post-mortem examination; but it was quite clear that, though the operation did not relieve the symptoms, it was perfectly successful in establishing a fistulous communication with the stomach in a most unpromising subject, and though the operation might be held responsible for not keeping the patient alive, it certainly was not responsible for his death. Had he lived longer I should have discovered whether a fistula produced in this way was likely to prove unduly large ; but my belief is that, owing to the smaller surface of stomach exposed at the bottom of the wound and the more complete closure of the external wound, the fistula has greater opportunities of contracting and is less likely to form a patulous opening than is the case with Howse's method. At the same time, if advisable, a metal tube of very small diameter could be used, which would give as narrow a fistula as could be desired.

Rodney-street, Liverpool.

\section{A. CASE OF \\ PERITONITIS WITH EFFUSION TREATED BY LAPAROTOMY.}

BY D'ARCY POWER, M.A. OxON., F.R.C.S. ENG., \&c., SURGEON TO THE VICTORIA HOSPITAL FOR CHILDREN, CHEISEA, AND

THw surgical treatment of abdominal tuberculosis in children has recently evoked so much discussion both at home and abroad that the present case may be read with interest by all who have to treat these troublesome and dangerous cases. I am indebted to my house surgeon (Mr. C. J. Harrison) and to Mr. Brightman, the medical officer at the Victoria Convalescent Home, Broadstairs, for the notes of the case.

A boy fourteen years of age was admitted into the Victoria Hospital for Children, Chelsea, under the care of Dr. Dawtrey Drewit on June 26th last. For $a$ month be had been wasting, and for the fortnight preceding his admission he bad been obliged to stay away from his work. He had suffered for three weeks from diarrboea, and for a fortnight he had complained of a cough and of night sweats. His abdomen had bcen swelling for a week before his admission, and he had vomiled twice. The patient was an anæmic and emaciated lad, with a uniformly distended abdomen, the skin being stretched and shiny. The umbilicus was flattened, and for an inch round it there was a bright-red blush as though an abscess were pointing. There was a similar patch of redness midway between the umbilicus and the ensiform cartilage; this patch felt odematous and appeared to communicate with the one lower down. The abdominal walls were so rigid that nothing could be felt through them. The flanks were resonant, but a distinct thrill could be transmitted from one side of the abdomen to the other. The lungs appeared to be healthy, and the urine was free from albumaen. The temperature was $105^{\circ} \mathrm{F}$., the pulse being 120 . On the day after his admission (Jane 27th) an incision was made in the middle line of the abdomen halfway between the umbilicus and the ensiform cartilage, from which two pints of a dark yellowish-red fluid escaped. This fluid coagulated spontaneously into a thick jelly like 
mass bout five minutes after its removal. It became almost, solid on boiling; microscopically it was found to be free from pus corpuscles. The wound was closed and dressed with cyanide gauze. The patient bore the operation well, and his temperature began to fall steadily and continuously until it became normal. The wound healed by first intention, and on July 12th, fourteen days after the operation, he was sent to our convalescent home st Broadstairs, where he continued in good health until Sept. 5th. He then complained of pain in his right side and of a troublesome cough. Physical examination showed that the chest morements on the right side were diminished, and that there was a distinct friction sound. On the next day neither breath sounds nor vocal resonance could be detected upon this side, and the chest was absolutely dull. There was some dyspnoea on Sept. 8th, therefore Mr. Brightman aspirated the chest below the angle of the scapula until the patient, began to congh. Two pints of clear fluid containing some thakes of lymph were drawn off, to the evident relief of the patient. As there was still some dulness with slight dyspnos on the 17 th, the chest was again aspirated, and a vint of clear fluid was withdrawn. The operation of paracentesis was again performed on the $27 \mathrm{th}$, when the fluid was found to be slightly greenish in colour, but not at all purulent. On Oct. 7th it was noted that there was absence of rocal fremitus on the right side, with dulness on percussion, faint breath sounds, and impairment of vocal rosonance. On Nov. 12th the physical signs had materially inuproved, and the temperature had been normal since Oct. 31st. He returned to London at the end of November. 1 saw him on Nov. 30th and again on Dec. 14th, and found that he was in excellent condition, except for evidence that his right pleura was thickened. His abdomen appeared to be perfectly sound. There was no positive evidence of tubercle in this case ; but, considering the character of the peritonitis and of the pleurisy, I have but little hesitation in assuming that the effusions were tuberculous in origin.

Remarks.-This case presents many points of surgical as well as of purely scientific interest. Thus the external appearances were distinctly misleading, for they all pointed to a purulent effusion into the abdomen, when in reality the poritonitis was of an acute plastic type. The spontaneous coagulation of the fluid shortly after its removal from the body was in accord with all that is known of the behaviour of the secretions of acutely inflamed serous membranes. The withdrawal of a fluid with so great a tendency to clot must necessarily have been productive of benefit to the patient by freeing him from much of the material likely to produce bands of adhesion with their attendant evil effects.

Why a simple incision into the abdomen and the evacuation of its contained fluid sometimes lead to a permanent cure in cases of peritoneal effasion cannot be satisfactorily explained. The experiments of Kischenski in Russia and of Bumm in Germany seem to afford a clue to the rationale of the process. Kischenski ${ }^{l}$ produced tuberculous peritonitis artificially in rabbits and guinea-pigs. He then performed laparotomy. On killing the animals five or six days afterwards he found that many of the bacilli were included in round cells, while if the animals were kept alive for from six to twelve days after the operation it was found that the micro-organisms had almost completely disappeared and that a considerable quantity of new connective tissue had formed. In the control animals, on the other hand, whose abdomens had not been opened, the bacilli in the peritoneum were most frequently found outside the cells, and there was no new growth of connective tiasue. Bumm's researches are of equal importance." $\mathrm{He}$ examined sections of the peritoneum taken from a woman corty years of age upon whom he had performed laparotomy twice in eight weeks for the relief of tuberculosis. The peritoneum on the first occasion contained typical tuberculous nodules. At the second operation, eight weeks later, the traberculous nodules on the surface of the peritoneum were found to be infiltrated with round cells and retracted by the cicatricial contraction of the neighbouring tissues, whilst the giant cells were completely destroyed. The woman remained wall at the time when the case was reported eighteen months after the operation. In this case, therefore, as well as in Kischenski's animals, it appears as though "laparotomy acted by leading to an infiltration of the tuberculous nodules with round cells, accompanied by, or leading to, their fibroid

1. Abstract of a paper in Russian in the Centralblatt iür Chirurgie, No. $40, p, 863,1893$.

Gitrungsberichte der Physikalisch-Medicinischen Gesellschaft zu Wiurnbirg, 1893, p. 7 . change, or, in the words of modern patrologists, that laparotomy causes an excitation of the phagocytic properties of the cells."

Something of the same kind appears to have happened in the case which $I$ here record. It is evident that the conditions which led to the peritoneal effusion were suddenly and permanently arrested, apparently by some purely local cause. The disease progressed, the other large serous sacs where the local arresting cause was not acting were next attacked, and there was a pleural effusion. The pleura was in turn placed under conditions as nearly as possible similar to those which had been effective in the case of the peritoneum, and with an equally satisfactory result. It was impossible to evacuate the pleura as completely as was done in the case of the abdominal cavity, and the beneficial effects were therefore slower in showing themselves. An almost exactly parallel instance occurs in those passive tuberculous effusions into the bursæ near joints which are crmmonly called "Baker's cysts." It has long been known that such cysts are capable of being cured by aspiration. The disease, however, progresses, and the neighbouring joint sooner or later becomes disorganised, apparently by an independent infection - at any rate, not by a simple extension of inflammation from the bursa, which may have completely disappeared. Little importance, of course, can be attached to a single case, but if individual cases are successively reported a sufficient body of evidence will presently be accumulated from which more or less satisfactory conclusions can be drawn in regard to the surgical treatment of even so complex a disease as tuberculous peritonitis.

Bloomsbury.square, W.C.

\section{CHLOROBROM IN SEA-SICKNESS.}

\section{By JOHN A. BOYD, M.B., C.M. Glasg.,}

ASSISTANT PHYSICIAN TO THE BELYIDERE HOSPIIAL, GLASGOW.

DuRING the last voyage when I was surgeon to the City of Bome I had opportunities of testing the value of chlorobrom in cases of sea-sickness, and in the remarks I have to make I propose to speak of it, first, as a prophylactic, and, secondly, as a remedy after the sickness has commenced. A few hours after our departure on Aug. 24th I administered the solution in drachm doses to three lady passengers, all of whom had never been to sea before. One of them was slightly sick on the following afternoon and another dose was given, which produced refreshing sleep. The next morning she was able to be on deck and remained well throughout the voyage. The other two ladies had no sickness, drachm doses being given at bedtime for the first four nights. They were enjoined not to take soup, vegetables, or pastry, and for breakfast to have only weak tea and toast. A female passenger, six months pregnant, when $I$ saw ber for the first time on the second day out was retching and complained of severe pain over the sacral region. She had the feeling, she told me, as "if she were about to miscarry." I gave her a dose of two drachms, which was retained. The retching ceased, and in the course of half an hour she fell asleep. Next morning she was so well that she could go on deck and had no return of the mal-de-mer. In this and on the return voyage $I$ tried it in a great many cases where vomiting and retching had continued for twenty-four hours, and in the great majority of them the patients, after a refreshing sleep, had no return of these symptoms. In some cases, however, although sleep followed the administration of the solution, the vomiting returned on the following morning. This I attributed to constipation, for whenever the bowels were freely opened by a saline aperient the patient soon recovered. If previously to embarkation the prime vice are moved, and if during the first few days on shipboard attention is paid to the diet, I am convinced that regular doses of this drug will secure to passengers immunity from seasickness. If, moreover, these precautions are not taken I am no less certain that the solution will, at least, cat short an attack of the malady.

Sandyford-street, Glasgow.

UNIVERSITY OF DURIIAM.-At the convocation held on the 12th inst. the M.D. degree of this university was conferred on the following two gentlemen :- Joseph G. Jeffreys and Fleming M. Sand with. 